\title{
Жизненные циклы экопоселений
}

\section{Е.В. Кузнецова}

Елизавета Владимировна Кузнецова, аналитик, Проектно-учебная лаборатория муниципального управления, НИУ ВШЭ. 101000 Москва, ул. Мясницкая, д. 20.

E-mail: evkuznetsova@hse.ru

Аннотация. Экопоселения - одна из форм идейной общины, ставящая своей целью организацию экологически чистого пространства для совместного проживания группы людей. Самым распространенным типом экопоселений в России являются поселения родовых поместий. В рамках статьи рассматриваются ключевые факторы, влияющие на развитие родовых поместий, производится анализ его ключевых этапов. В исследовании подтвердилось предположение о присутствии определенных стадий, через которые проходят поселения родовых поместий в процессе формирования, выделены факторы успешности.

В целом поселенцам необходимо следовать нескольким правилам, которые определяют успешную групповую динамику. Во-первых, серьезно относиться к отбору в члены поселения, что играет важную роль не только на экономическом уровне (опытные поселенцы видят, каких ресурсов не хватает человеку для развития своего поместья), но и на уровне коммуникации. Во-вторых, как можно раньше формализовать экономическое взаимодействие: сформировать четкий процесс голосования за инициативы, выбрать инициативную группу, которая будет заниматься сбором средств. В-третьих, быть готовыми к некоторому разочарованию и уходу членов, ожидания которых не подтвердились. В-четвертых, постараться реализовать максимально возможно большее количество проектов на первых этапах строительства поселения, чтобы таким образом сильнее сплотить людей и сформировать мини-группы, в рамках которых жителям было бы комфортно взаимодействовать друг с другом.

Ключевые слова: экопоселения, поселения родовых поместий, анастасийцы, социальная структура сельских сообществ, местные сообщества, рурализация, сельская жизнь, групповая динамика, психология

DOI: 10.22394/2500-1809-2021-6-1-170-179

Экопоселения - одна из форм идейной общины, ставящая своей целью организацию экологически чистого пространства для совместного проживания группы людей. Самым распространенным типом в России являются поселения родовых поместий. Изначально идея родового поместья была предложена Владимиром Мегре в книге “Анастасия) - первой из 10 книг серии “Звенящие кедры России». Популярность книг породила развитие движения, и поселения родовых поместий (далее - ПРП) стали повсеместно появляться во многих регионах России. Основная идея последователей движения - анастасийцев - в необходимости иметь собственный гектар 
земли в безвозмездном пользовании и передавать его из поколения в поколение. Своя земля необходима для того, чтобы получать “родовую энергию» и восстановить способности, утраченные человечеством в ходе истории. Гектар земли - минимум для самовоспроизводимости и создания максимального биоразнообразия. Постройка своего поместья - создание рая на земле своими руками. Здесь важно, что подразумевается именно проживание в поселении - то есть построение локального сообщества, объединенного идеологической программой. Обычно поселения родовых поместий располагаются в сельской местности в относительной удаленности от городов, что, с одной стороны, обеспечивает экологичность проживания, но с другой - требует поиска новых источников средств к существованию.

Исследователи изолированных сообществ обратили внимание на то, что поселения родовых поместий проходят через схожие этапы на пути формирования и развития - жизненные циклы (Задорин и др., 2014; Позаненко, 2016). В рамках данной работы предпринимается попытка рассмотреть эти жизненные циклы не из социологической, а из психологической перспективы и понять, применима ли какая-то из моделей групповой динамики для анализа того, как меняются отношения внутри поселения.

Исследование было проведено в рамках бакалаврской дипломной работы по специальности (Психология» под руководством Артемия Алексеевича Позаненко.

\section{Методология исследования}

Поселения, охваченные исследованием, расположены в 12 областях России, от Новосибирской области и до Краснодарского края, в 17 поселениях были проведены 26 полуструктурированных интервью. В качестве основного метода анализа данных выбран тематический анализ (Холтон, 1981) с последующим построением модели динамики отношений внутри поселений и фокторами, на нее влияющими.

\section{Факторы, влияющие на групповые процессы в поселениях родовых поместий}

Зимовка. Важным понятием для всех родовых поместий, считающимся в том числе одним из критериев его успешности, является процент зимующих семей - доля людей, проживающих в поместье круглогодично. По данным ресурса “Поселения.ру» на май 2020 года, из 420 зарегистрированных поселений только в 146 люди остаются зимовать (Родовые Поселения, 2020). Зимовка является важным критерием, влияющим не только на формирование опыта и самовосприятие поселенца, но и на групповую динамику. Говоря о зимовке, информанты вспоминают сложности быта в завалах
171

E.B. Кузнецова

Жизненные циклы экопоселений 
172 снега, нехватку общения, скуку, связанную с малым количеством людей в поселении.

Общие проекты. Основным связующим фактором в поселениях является наличие совместных проектов. Первоначально они связаны с инфраструктурными задачами, например, уходом за дорогами, их расчисткой. Когда первичные потребности удовлетворены, поселенцы начинают облагораживать пространство вокруг себя. Так, в некоторых поселениях есть (поляна) - общая территория, на которой происходят внутрипоселенческие сборы. На этом же этапе возникают проекты по строительству общего дома или клуба. В таком доме в дальнейшем проводятся мероприятия, отмечаются праздники. Иногда жители начинают организовывать кружки "для своих». Во время проживания в поселении может возникнуть потребность в общей электрификации, в связи с недостаточной мощностью личных генераторов и солнечных батарей. Далее появляются образовательные проекты для детей, например, своя школа, детский сад, драматический театр. Повсеместно и вне зависимости от того, построен ли общий дом, распространены детские лагеря (для своих», а иногда и для детей из близлежащих деревень.

Kонфблкты. Очень важную роль в формировании группы играют нормативные способы разрешения конфликтов, а также действия при обострении конфликтных ситуаций. Большинство конфликтов в поселениях родовых поместий возникают на двух основаниях: материальной или идеологической.

Конфоликты на материальной почве в основном прагматического характера: часты случаи, когда люди, например, отказываются от взносов на расчистку дорог и другие базовые инфраструктурные нужды, потому что по каким-то причинам считают этот сбор необоснованным (так, на расчистку дорог не хотят сдавать деньги те, у кого нет машины), из-за чего в поселении происходит глобальный конфрликт, и часть людей либо дистанцируется от общества, либо поселение делится на почти не взаимодействующие между собой группы.

Идеологические конфликты случаются на более ранних стадиях развития группы. Так, многие пытаются (вслепую» применять принципы, описанные в книгах Мегре, и категорично настаивают на исключительно экологичном образе жизни, например, отказываясь от центрального электроснабжения и протестуя против электрификации поселка. Этим поселенцы не только реализуют таким образом понимаемую экологичность, но и манифестируют независимость от (системы» - государства.

Лидерство. В основном в поселениях родовых поместий преобладает трансформационное лидерство: член сообщества придумывает какой-то проект, и вокруг него объединяется инициативная группа, которая этот проект развивает. Формальным лидером в поселениях, зарегистрировавших юридическое лицо, может считаться тот, кто является его председателем. Также есть практика 
выкупа всей земли в собственность одним человеком, и последующая его продажа. Собственник земель, таким образом, может играть ключевую роль именно в заселении территории: ему принадлежит решающее слово при приеме новых членов. Таким формальным лидерством можно манипулировать: в некоторых поселениях идут судебные распри по поводу сбора денег и их растраты. В целом же лидерские амбиции поселенцами нивелируются и порой осуждаются: основным базисом для комфортного взаимодействия внутри группы является равенство социальных статусов.

Мотивачия. Важным фактором успешного формирования групповой динамики выступает мотивация поселенцев. Так, поселения делятся на строго и не строго идеологические. Это различие не только диктует особенности отбора поселенцев, но и порождает большое количество споров. Многие жители ПРП сознательно уходят от ассоциации себя со стигматизированным ныне понятием (анастасиец), не без оснований считая, что общество рассматривает «Звенящие кедры России) как секту, и не желая по этой причине маргинализироваться. Более того, неполное следование идеологии движения информанты рассматривают как позитивный фактор для привлечения новых последователей, если не движения (Звенящие кедры России», то по крайней мере людей, стремящихся к экологичному образу жизни.

Правила поселения. Близким к мотивационному критерию является наличие правил поселения, то есть каких-либо прописанных норм, соблюдение которых ожидается от вновь прибывших. Так, во многих ПРП существует запрет на межевание территории, чтобы не нарушалась общая концепция. Поскольку по канонам (Звенящих кедров» необходимо придерживаться вегетарианства, неодобрительно относятся к животноводству, иногда желающие им заниматься вообще не принимаются в поселение, а иногда - маргинализируются.

Правила отбора членов поселения. На этот фактор успешности формирования поселения влияет в первую очередь юридический аспект: в некоторых поселениях земля находится в личной собственности, и продать ее можно кому угодно, однако гектар земли сельхозназначения вряд ли может использоваться для других целей, кроме построения родового поместья. В поселениях со строгим отбором обычно ниже абсентеизм и текучка: поселенцы уже на этапе знакомства не позволяют покупать землю тем, кто, по их мнению, будет не способен на ней проживать (не хватит денег, поддержки, слишком молод, одинок). В одних поселениях прием в члены происходит путем голосования простым большинством, в других - требуется единогласное одобрение. Также есть практика «испытательного срока», когда желающие поселиться приезжают на субботники и гостевые дни и показывают себя (в деле».

И последним выделенным мной фактором оказалась причина отъезда из поселения: она влияет на динамику косвенно. Потеря члена группы в любом случае негативно отражается на групповом
173

E.B. Кузнецова

Жизненные циклы экопоселений 
174 процессе, но причина, по которой это происходит, также важна. В основном люди покидают поселение потому, что не справляются COBPEMEHность с бытовыми и/или финансовыми трудностями; в таком случае они возвращаются обратно в город и используют поместье как дачу или пытаются продать. Еще одной причиной может быть слабая инфраструктура: например, когда в семье несколько детей, а школа далеко, приходится менять место жительства. Причиной отъезда может стать чрезмерная эскалация конфликтов и несовпадение взглядов на желаемый образ жизни, из-за чего принимается решение переехать в более (дружественное» по мировоззрению поселение.

\section{Модель формирования группы в экопоселении}

Если в динамике наблюдать историю развития группы в поселениях родовых поместий и пытаться сверить их с предложенными в прошлом концептуальными моделями развития группы, наиболее применима, на наш взгляд, модель развития группы Такмена (Tuckman, 1965). По Такмену, группа проходит через стадии формирования, конфоликта, нормирования и функционирования. В родовых поместьях процесс идет сходным образом. Так, поселение начинается с инициативной группы - нескольких людей, принявших решение сформировать свою общину, и редко - с одного инициатора. Поиск единомышленников осуществляется через порталы (Анастасия.ру», “Поселения.ру» и группы в социальных сетях. Эта стадия соответствует стадии формирования группы по Такмену.

Далее происходит поиск места для будущего поселения, решение юридических задач, регистрация. Параллельно с этим через всевозможные каналы коммуникации идет активный рекрутинг новых членов. Поскольку рекомендуемый В. Мегре размер поселения составляет 150 поместий, то часто ищется земельный участок площадью более 100 гектаров. На этом же этапе, при наличии рядом с таким участком деревни, идет знакомство и попытки дестигматизировать группу заранее - чаще всего про (Звенящие кедры» поселенцы не распространяются. Далее, когда земля размежевана и будущие поселенцы приступают к построению поместий, в группе процветают взаимопомощь и взаимовыручка. Когда же поместье построено, и людей начинает затягивать тяжелый и непривычный для горожан быт, группа сдвигается на стадию конфоликта. Случаются бытовые разногласия в рамках инфраструктурных проектов, часть людей, особенно из рекрутированных в процессе формирования поселения, переходят в абсентеизм и не принимают активного участия в жизни группы. На данном этапе часто возникают структурные конфликты, и поселение может даже разделиться на два юридических лица и полностью рассориться. Далее группа переходит в стадию нормирования: либо формулируются нормы для болееменее бесконфоликтного сосуществования, то есть выбирается дата 
обязательных для посещения общих собраний, а совместные мероприятия не проводятся, и группа ведет разобщенный образ жизни; либо удается выбрать приемлемый для всех принцип принятия решений, например вечевой, предложенный Владимиром Мегре, и группа выходит из конфоликта готовой к продолжению совместной деятельности и осуществлению различного рода проектов. На стадии нормирования важно выделить необязательность участия в общественных инициативах (организация ярмарок, лагерей и пр.), так людей перестает тяготить ощущение, что они не обладают свободой выбора, а потому они начинают чувствовать себя комфорортнее. Далее группа переходит на стадию функционирования: поселенцы понимают, что не обязаны (со всеми дружить», и общаются в кругу тех, с кем комфортно. При появлении инициатив реализуются совместные проекты. Текучка присутствует, но по личным причинам, а не из-за конфоликтных ситуаций.

\section{Динамическая модель формирования отношений В экопоселениях}

На основе выделенных факторов и самооценки успешности поселений жителями можно построить модель формирования динамики отношений внутри поселения и выделить наиболее важные на каждом из этапов.

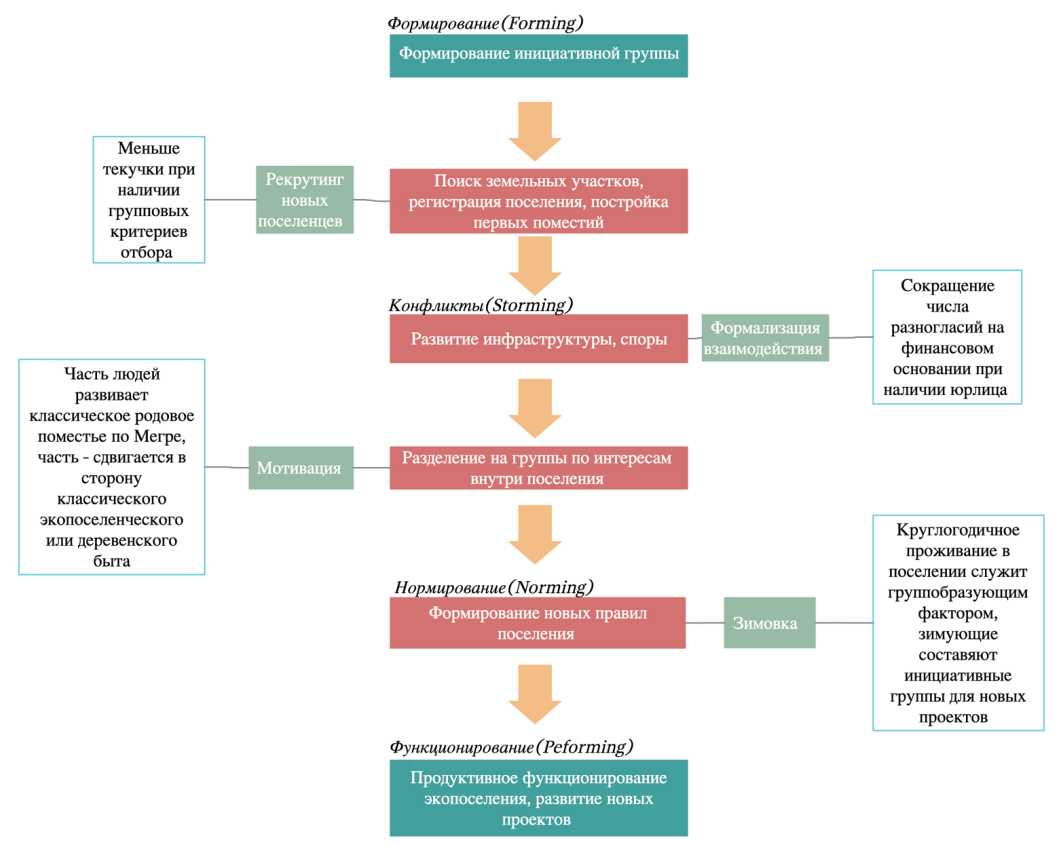

Схема 1. Групповая динамика в поселениях родовых поместий
175

E.B. Кузнецова

Жизненные циклы экопоселений 
176 На представленной схеме можно наблюдать, что играет наиболее важную роль при переходе группы к следующему этапу функционирования. Рассмотрим подробнее каждый из выделенных критических факторов для перехода группы к следующему этапу.

На этапе формирования поселения особенно важны ритуалы рекрутинга новых поселенцев (они значимы и на последующих этапах, но именно на начальном играют критическую роль). Так, если в поселение принимают без первичного знакомства с соседями, впоследствии происходит эскалация конфликтов на фоне разницы интересов и характеров. В случаях же когда для переезда в поселение необходимо пройти обряд инициации (знакомство со всеми жителями, анкетирование), число конфликтов и текучка снижаются. Приведу описание порядка принятия в одно из крупных ПРП.

«Рекомендуемый сценарий: семья приезжает на гостевой день, знакомится. Может пожить хотя бы неделю у нас, можно пожить в общем доме или в палатках (в теплое время). Приветствуется, если семья поучаствовала в дне общения (каждая 3-я суббота месяиа) и в субботнике (каждая 4-я суббота месяца). Также можно походить по поместьям, пообщаться лично, познакомиться с каждой семьей. После чего заявить о своем желании вступить. Вступить можно на очередном собрании каждую первую субботу месяиа. Вступающая семья рассказывает о себе на собрании, о своих планах, а каждый из жителей может задавать любые интересующие их вопросы. Типичные вопросы: как вы собираетесь зарабатывать на своей земле? Как планируете строиться? Чем планируете заниматься на своем поместье? Есть ли образ своего поместья? И так далее. Потом семью просят временно удалиться, и идет внутреннее обсуждение и голосование. Если все голосуют за, то семья принята. С этого момента у нее начинается испытательный срок, за который она должна построиться и переехать. Сейчас этот срок равен 3 годам, но может обсуждаться индивидуально для каждой семьи. Спустя год подводятся первые итоги переезда семьи. Есть возможность вступить в постоянные жители, если семья выполнила все условия и переехала жить в поселение раньше. Переход в статус постоянных осуществляется на очередном собрании».

Так, с потенциальными поселенцами происходит не только знакомство, но и проверка их на деле: поселенцы смотрят на то, как потенциальный сосед взаимодействует с другими людьми, работает. Более того, присутствует даже испытательный срок с целью недопущения простаивания земли без хозяина.

Когда в поселении начинают развивать инфраструктуру, критически важно формализовать взаимодействие внутри поселения. Так, при регистрации юридического лица при голосовании большинством за ту или иную статью расходов исчезают конфоликты по финансовым вопросам (сдавать/не сдавать средства на что-то, что конкретный поселенец может считать не нужным для себя). 
«Например, ежегодно собираемся для ремонта дорог. Мы ежегодно проводим ревизию, плановое обслуживание. ЛЭП есть, у нас есть своя КТП, трансборматорная подстаниия, есть свои электросети, они принадлежат ДПН юрличу, в общем балансе находятся, есть план передать их государству, чтобы не обслуживать. Расчетный счет, ежегодный счет. Бухгалтер наемный на аутсорсинге. Есть взнос ежегодный обязательный 2400, есть челевые взносы на ремонт дорог. Наш домик тоже был за счет цеелевого взноса, соответственно все чеки, всю документацию можно посмотреть. 6 тысяч мы приняли на общий дом, и раз-

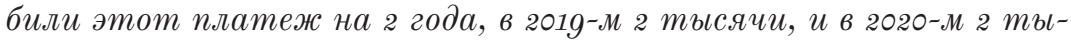
сячи, итобы людям было комбортно платить. Все офорлляется протоколом общего собрания. Если кто-то не согласен, к ним подходят люди тут же, на собрании, и общаются, рассказывают. И обгясняют, ито так и так, это необходимость. Должна быть какая-то культурная составляющая жизни. Те, кто был жестко против, меняли свою точку зрения пряло на собрании. $A$ вообще бывает, ито действительно голоса против, и либо вопрос снимается на какое-то время, откладывается, и если человек жестко против, то мы либо переносим принятие решения, либо делается запись в протокол. Но в основном такие вопросы поднимаются, насущные и политкорректные. Подразумевается, ито по таким вопросам нет разногласий, то есть стараемся сводить вопросы в модуль жизненной необходимости. Чтобы вопросов не было».

Так, формализация и протоколирование взаимодействия значительно снижают уровень разногласия и помогают нормализовать процесс принятия решений. Более того, есть способ решения проблемы несогласия, когда оно протоколируется. Принятие решения не простым большинством, а абсолютным положительно влияет на атмосферу общих собраний: те, кто не понимает смысл реализации проекта, чувствуют себя услышанными.

Далее группа начинает делиться на подгруппы по изначальной мотивации и интересам: кто-то разочаровывается непосредственно в идеях (Звенящих кедров» и переходит в формат более традиционной экожизни, кто-то обращается к сельскому образу жизни и реализует практики, изначально не соответствующие догматам анастасийства, например, начинают выращивать животных на убой. Некоторые же продолжают радикально придерживаться правил, рекомендуемых Анастасией, чем порой вызывают снисходительное отношение соседей, изменивших подход на более реалистичный.

Но изначально объединяющий фактор все равно идеологический. Процитируем одну из информанток, круглогодично живущую в поселении:

«Hу mут cmоит говорить о тол, ито мы все-таки были вдохновлены единой идеей. И когда эта идея раскрывалась через книги, 
178 каждый сам понимал, ито именно он хочет, и какого пруда ему будет достаточно для самовосстанавливающейся экосистемы».

современность Развитие поселения требует новых правил взаимодействия, менее идеалистичных и более гибких. По мере формулирования этих правил происходит некоторая внутренняя динамика: люди, круглогодично живущие в поселении, создают инициативные группы, которые занимаются развитием необходимых поселению побочных проектов. Обычно сначала строятся клуб или общий дом, затем - образовательные учреждения (детские сады, кружки), при успешности которых запускаются коммерческие или культурные проекты (досуговые центры).

Важно, что перед началом реализации совместных проектов жителям необходимо удовлетворить базовые потребности:

«В челлом все хорошо. Конечно, было бы луише, итобы был больще общий дом для общих праздников и собраний, итобы были лучше дороги, своя школа и так далее. Все это нужно просто строить нам. Я считаю, ито сейчас у нас этап, когда уже много семей заканчивают строительство своего жилья и закрываюот первые необходимые потребности, а значит, уже все больше будет времени на общие дела».

Успешно пройдя через эти стадии, экопоселение становится устойчивым с точки зрения своего дальнейшего развития и состава, исчезают конфоликтные ситуации, и обстановка становится более гармоничной. Поселение использует подходящие именно им рычаги регулирования конфликтов: в некоторых угрожают привлечением органов власти, в некоторых - пытаются решить конфоликты мирным путем - (по душам) поговорив с несогласными.

Так, поселения родовых поместий, при соблюдении некоторых базовых правил взаимодействия, становятся комфортной средой для проживания и самореализации. Успешное прохождение стадий развития экопоселения гарантирует устойчивость его дальнейшего функционирования, а принятие наиболее комфортных для каждого поселенца условий сосуществования может уменьшить количество возникающих конфликтов.

\section{Библиография}

Задорин И.В., Мальцева Д.В., Хомякова А.П., Шубина Л.В. (2014). Альтернативные сельские поселения в России: стихийная внутренняя эмиграция или осознанный трансфер в будущее // Лабиринт. Журнал социально-гуманитарных исследований. T. 2. C. $64-77$.

Позаненко А. (2016). Самоизолирующиеся сообщества - Социальная структура поселений родовых поместий // Мир России. Т. 25. № 1. С. 129-153.

Родовые поселения: статистика (2020). http://poselenia.ru/poselenie Холтон Дж. (1981). Тематический анализ науки. М.: Аспект Пресс.

Tuckman B.W. (1965). Developmental sequence in small groups //Psychological Bulletin. T. 63. № 6. P. 384-399. 


\section{Life cycles of ecovillages}

Elizaveta V. Kuznetsova, Analyst, Design-Training Laboratory for Municipal Administration, National Research University Higher School of Economics. 101000, Moscow, Myasnitskaya St., 20. E-mail: evkuznetsova@hse.ru

Abstract. Ecovillages are forms of the ideological community that aims at providing a group of people with an environmentally friendly space for living together. Some kind of the contemporary estate is the most widespread type of ecovillages in Russia. The author considers the key factors affecting the development of such ecovillages and its main stages. The study confirmed the author's assumption about the certain stages in the ecovillage development and about the factors of its success. In general, villagers have to follow several rules that ensure the successful group dynamics. First, to select members of the settlement very carefully, because this choice has an important impact not only on the economy (experienced settlers understand what resources a person lacks for the development of his estate) but also on communications. Second, to formalize the economic interaction as fast as possible: to ensure a clear process of voting for initiatives and to choose an initiative group responsible for fundraising. Third, to be ready for disappointments and departures of members whose expectations were not met. Fourth, at the first stages of the ecovillage development, to try to implement as many projects as possible in order to unite people and form mini-groups for the comfortable interaction of ecovillagers.

Key words: ecovillages, settlements of estates, anastasians, social structure of rural communities, local communities, ruralization, rural life, group dynamics, psychology

\section{References}

Zadorin I.V., Maltseva D.V., Khomyakova A.P., Shubina L.V. (2014) Alternativnye selskie poseleniya v Rossii: stihijnaya vnutrennyaya emigratsiya ili osoznanny transfer v budushchee [Alternative rural settlements in Russia: Spontaneous internal migration or a conscious path to the future]. Labirint, vol. 2, pp. 64-77.

Pozanenko A. (2016) Samoizoliruyushchiesya soobshchestva - socialnaya struktura poselenij rodovyh pomestij [Self-isolated communities - social structure of estate settlements]. Mir Rossii, vol. 25, no 1, pp. 129-153.

Rodovye poseleniya: statistika [Estate Settlements: Statistical Data] (2020). http://poselenia.ru/poselenie.

Holton G. (1981) Tematichesky analiz nauki [Thematic Analysis of Science], Moscow: Aspekt Press.

Tuckman B.W. (1965) Developmental sequence in small groups. Psychological Bulletin, vol. 63, no 6, pp. 384-399. 